\title{
NELFE promoted pancreatic cancer metastasis and the epithelial-to-mesenchymal transition by decreasing the stabilization of NDRG2 mRNA
}

\author{
LILI HAN $^{1}$, YING ZAN $^{1}$, CHEN HUANG $^{2}$ and SHUQUN ZHANG ${ }^{1}$ \\ ${ }^{1}$ Department of Oncology, The Second Affiliated Hospital, College of Medicine, Xi'an Jiaotong University, \\ Xi'an, Shaanxi 710004; ${ }^{2}$ Key Laboratory of Environment and Genes Related to Diseases, \\ Ministry of Education of China, Xi'an Jiaotong University, Xi'an, Shaanxi 710061, P.R. China
}

Received July 2, 2019; Accepted September 20, 2019

DOI: $10.3892 /$ ijo.2019.4890

\begin{abstract}
Negative elongation factor E (NELFE) has been demonstrated to promote cancer progression as an RNA-binding protein (RBP). However, the expression patterns, biological role and molecular mechanism of NELFE in pancreatic cancer (PC) remain largely unknown. The expression levels of NELFE in 120 pairs of PC tissues and adjacent non-tumor clinical samples collected from patients with PC were examined via reverse transcription-quantitative (RT-q) PCR and immunohistochemistry. The mRNA expression levels of NELFE, N-Myc downstream-regulated gene 2 (NDRG2), c-Myc, survivin and cyclin D1 were detected via RT-qPCR. The protein expression levels of NELFE, NDRG2, total $\beta$-catenin, nuclear $\beta$-catenin, cytosolic $\beta$-catenin, E-cadherin, $\mathrm{N}$-cadherin and Vimentin were measured by western blotting. NELFE and NDRG2 were then knocked-down by short hairpin (sh)RNA. PC cell proliferation was detected by MTT and colony formation assays. Invasion and migration were detected by transwell assays. The interaction between NELFE and NDRG2 was detected by luciferase reporter assays, mRNA decay assays and RNA immunoprecipitation. NELFE expression was increased in PC tissues compared with the paired non-cancerous tissues. NELFE expression was upregulated in PC cells when compared with normal pancreatic cells
\end{abstract}

Correspondence to: Professor Chen Huang, Key Laboratory of Environment and Genes Related to Diseases, Ministry of Education of China, Xi'an Jiaotong University, 157 Xiwu Road, Xi'an, Shaanxi 710061, P.R. China E-mail: 498730224@qq.com

Professor Shuqun Zhang, Department of Oncology, The Second Affiliated Hospital, College of Medicine, Xi'an Jiaotong University, 277 Yanta West Road, Xi'an, Shaanxi 710004, P.R. China

E-mail: 61439376@qq.com

Key words: RNA-binding protein, negative elongation factor E, pancreatic cancer, epithelial-to-mesenchymal transition, N-Myc downstream-regulated gene $2, \beta$-catenin
(HPDE6-C7). The present study revealed that knockdown of NELFE inhibited the proliferation, invasion and migration of PC cells. In addition, transfection of the sh-NELFE vector inhibited the epithelial-to-mesenchymal transition in PC cells by suppressing the expression and nuclear accumulation of $\beta$-catenin. Further mechanistic studies revealed that NELFE activates the $\mathrm{Wnt} / \beta$-catenin signaling pathway by decreasing the stabilization of NDRG2 mRNA in PC. To the best of our knowledge, these results revealed the promotional function of NELFE on PC tumorigenesis and metastasis for the first time, helping to provide a promising strategy for the treatment of patients with PC.

\section{Introduction}

Pancreatic cancer (PC) is the third leading cause of cancer-associated mortality worldwide (1), with a total of 1,619 cases succumbing to PC reported by China's Disease Surveillance Point System (DSPS) between 1991 and 2000 (2). Due to the high rate of metastasis and lack of effective treatment for patients with metastatic cancer, the overall 5-year survival rate of PC is $<10 \%$ (3). Thus, it is critical to further elucidate the molecular mechanisms underlying PC metastasis.

The epithelial-to-mesenchymal transition (EMT) is at least in part responsible for the metastatic progression of multiple types of cancer, and this process results in cancer cells losing epithelial features and acquiring mesenchymal features $(4,5)$. Among the various signaling pathways that contribute to the development of PC, the $\mathrm{Wnt} / \beta$-catenin signaling pathway plays a prominent role in the EMT and metastasis in PC (6). The expression and subcellular localization of $\beta$-catenin is closely associated with PC tumor formation and development. The activation of Wnt signaling occurs upon nuclear accumulation of $\beta$-catenin (7), which activates downstream target genes. Therefore, investigation of the pivotal upstream regulator of the Wnt/ $\beta$-catenin pathway is definitely warranted for a comprehensive understanding of the molecular mechanism underlying the metastasis and EMT of PC.

RNA-binding proteins (RBPs), which bind directly to the RNA of target genes, contribute to tumor biology and progression by regulating RNA at multiple levels, for example, 
through RNA stabilization, translation, localization and degradation (8-10). Although nearly 2,000 RBPs have been identified (11), the molecular mechanisms by which RBPs modulate human cancer progression remain largely unclear. Negative elongation factor E (NELFE) is one of the subunits of NELF, which is a multi-subunit that cooperates with DRB sensitivity-inducing factor (DSIF) and results in the inhibition of Pol II elongation (12). Recent research revealed that NELFE could also serve as an RBP oncogene in hepatocellular carcinoma through the regulation of MYC signaling (13). However, the expression patterns and the potential physiological functions of NELFE in other types of human cancer, including PC, remain largely unknown.

The present study investigated the role of NELFE in PC cell proliferation, migration and invasion and assess the correlation between NELFE expression in clinical PC tissues and prognosis. The aim of the present study was to determine whether NELFE is a potential therapeutic target and an effective predictive biomarker for patients with PC.

\section{Materials and methods}

Patients and tissue samples. The Ethics Committee of Clinical Research of Xi'an Jiaotong University (Xi'an, China) approved the present study, and written informed consent was obtained from each patient prior to the study start. The 120 pairs of PC tissues and adjacent non-tumor clinical samples were collected from patients with PC who underwent surgical resection at The Second Affiliated Hospital of Xi'an Jiaotong University between May 2013 and May 2015. The adjacent tissues were collected $\geq 5 \mathrm{~cm}$ away from the edge of PC cancerous tissue. Inclusion criteria were as follows: All patients were determined to have PC via pathological diagnosis and had not received chemotherapy, radiotherapy or immunotherapy prior to resection; and the exclusion criteria were as follows: Patients aged $<20$ and $>70$ years. Table I presents the clinicopathological data of the patients. Every pair of tissues observed in the present study contained both cancerous and distant non-cancerous tissues, and were frozen in liquid nitrogen immediately after surgery, and then stored at $-80^{\circ} \mathrm{C}$.

Immunohistochemistry. The immunohistochemistry assay was performed as previously described (14). The anti-NELFE antibody used in the immunohistochemistry assay was purchased from Beijing Biosynthesis Biotechnology (1:100; cat no. bs-19198R). The biotinylated goat anti-rabbit antibody (1:200; cat. no. A0279; Beyotime Institute of Biotechnology) was used as the secondary antibody. The diaminobenzidine tetrachloride (cat. no. P0203; Beyotime Institute of Biotechnology) was used for staining at $37^{\circ} \mathrm{C}$ for $10 \mathrm{~min}$.

Cell culture and transfection. The normal pancreatic cell line, HPDE6-C7, was purchased from CELLBIO Cell Center, and the PC cell lines, including PaCa-2, PANC-1, SW1990, AsPC-1 and $\mathrm{BxPC}-3$, were purchased from the American Type Culture Collection. All cells were cultured in Dulbecco's modified Eagle medium (DMEM; Sigma-Aldrich, Merck KGaA) supplemented with $10 \%$ fetal bovine serum (FBS; Gibco; Thermo Fisher Scientific, Inc.). The specific short hairpin (sh)-RNA vector (sh-NELFE and sh-NDRG2) to knockdown
NELFE or NDRG2 expression in PC and their control vectors were purchased from Genepharma. PC cells were cultured in 6-well plates until they reached $40-50 \%$ confluence, and the $50 \mathrm{nM}$ vectors were transfected into PC cells using Lipofectamine ${ }^{\circledR} 2000$ reagent (Invitrogen; Thermo Fisher Scientific, Inc.) according to the manufacturer's protocol. In order to establish stable clones, PC cells were expanded by trypsinizing after $48 \mathrm{~h}$, diluted and then seeded in a 96-well plates with DMEM containing 10\% FBS and $500 \mu \mathrm{g} / \mathrm{ml} \mathrm{G} 418$ (Gibco; Thermo Fisher Scientific, Inc.). The PC cells were inspected daily under the fluorescence microscope to ensure the colonies were derived from a single cell within a well. After 20-25 days selection, the PC cells were trypsinized and re-seeded into 24-well plates, and then into 6-well plates in DMEM containing 10\% FBS with $500 \mu \mathrm{g} / \mathrm{ml}$ G418. Finally, the NELFE or NDRG2 expression levels in the PC cells collected from G418 positive colony were assessed by reverse transcription-quantitative (RT-q) PCR and western blotting.

$R T$ - $q P C R$. RT was performed on $0.1 \mu \mathrm{g}$ total RNA, which had been extracted from PC cell lines or tissue by TRIzol ${ }^{\circledR}$ reagent (Invitrogen; Thermo Fisher Scientific, Inc.) to complementary DNA using a RT-PCR kit (ABI; Thermo Fisher Scientific, Inc.) $45 \mathrm{~min}$ at $50^{\circ} \mathrm{C}$. qPCR reactions were performed in triplicate using a SYBR Premix Ex Taq Real-Time PCR kit (Takara Bio, Inc.) according to the manufacturer's protocol. The housekeeping genes GAPDH, $\beta$-actin and Hydroxymethyl bilane synthase (HMBS) were selected to serve as the candidate internal controls in the present study, as they were steadily expressed at a similar level in the examined PC cell lines. All the three internal controls were expressed stably, and the RT-qPCR results calculated using the three internal controls were similar. GAPDH is taken as the internal control in the figures listed in the paper. The NELFE and NDRG2 mRNA Expression levels were examined using a relative quantification approach $\left(2^{-\Delta \Delta \mathrm{Cq}}\right.$ method) compared with the level of GAPDH (15), which is expressed at a similar level in the examined PC cell lines. The RT-qPCR thermocycling conditions were as follows: Initial denaturation $\left(90^{\circ} \mathrm{C}\right.$, $5 \mathrm{~min}), 40$ cycles of denaturation $\left(90^{\circ} \mathrm{C}, 10 \mathrm{sec}\right)$, annealing $\left(75^{\circ} \mathrm{C}, 6 \mathrm{sec}\right)$ and elongation $\left(75^{\circ} \mathrm{C}, 30 \mathrm{sec}\right)$, final elongation $\left(75^{\circ} \mathrm{C}, 10 \mathrm{~min}\right)$ and a final hold $\left(4^{\circ} \mathrm{C}\right)$. The primers used in the present study were as follows: NELFE: Forward, 5'-GCATAT CCATATGCAGGAATGCCTGGAGAAGTTCC-3', reverse, 5'-GCGGATCCTTATTCGGCCAGTCGGTAGATTAGC-3'; NDRG2: Forward, 5'-CACTCCAGTGACAGCACCTCT-3'; reverse, 5'-GGCTCCAACACCAACTCCAAT T-3'; and GAPDH: Forward, 5'-AATGGACAACTGGTCGTGGAC-3'; reverse, 5'-CCCTCCAGGGGATCTGTTTG-3'.

Western blotting. The protein was collected from PC cell lines via lysing by RIPA Buffer (Thermo Fisher Scientific, Inc.), and the protein concentrations were determined by BCA assays (Cell Signaling Technology, Inc.). Each of the samples were quantitatively released by the RIPA Buffer at the same concentration.

Total proteins (25 $\mu \mathrm{g}$ per lane) were separated via SDS-PAGE (10\% gel). The proteins were then transferred to polyvinylidene fluoride (PVDF) membranes (EMD Millipore) and blocked in 5\% skimed milk PBS with $0.1 \%$ 
Table I. Association between NELFE expressions and clinicopathological features in pancreatic cancer.

\begin{tabular}{|c|c|c|c|c|}
\hline \multirow[b]{2}{*}{ Variable } & \multirow[b]{2}{*}{ Total no. of patients $n=120$} & \multicolumn{2}{|c|}{ NELFE expression, $\mathrm{n}$} & \multirow[b]{2}{*}{ P-value } \\
\hline & & High & Low & \\
\hline Age, n (\%) & & & & 0.259 \\
\hline$<60$ years & $48(40.0)$ & 36 & 12 & \\
\hline$\geq 60$ years & $72(60.0)$ & 47 & 25 & \\
\hline $\operatorname{Sex}, \mathrm{n}(\%)$ & & & & 0.646 \\
\hline Female & $45(37.5)$ & 30 & 15 & \\
\hline Male & $75(62.5)$ & 53 & 22 & \\
\hline Chronic pancreatitis, n (\%) & & & & 0.546 \\
\hline Yes & $57(47.5)$ & 44 & 13 & \\
\hline No & $63(52.5)$ & 39 & 24 & \\
\hline Tumor size, n (\%) & & & & 0.04 \\
\hline$<2 \mathrm{~cm}$ & $42(35.0)$ & 34 & 8 & \\
\hline$\geq 2 \mathrm{~cm}$ & $78(65.0)$ & 49 & 29 & \\
\hline Differentiation, n (\%) & & & & 0.136 \\
\hline Well-moderate & $69(57.5)$ & 44 & 25 & \\
\hline Poor & $51(42.5)$ & 39 & 12 & \\
\hline Lymph-node metastasis, n (\%) & & & & 0.001 \\
\hline Yes & $69(57.5)$ & 39 & 30 & \\
\hline No & $51(42.5)$ & 44 & 7 & \\
\hline TNM stage, n (\%) & & & & 0.003 \\
\hline I-II & $63(52.5)$ & 51 & 12 & \\
\hline III-IV & $57(47.5)$ & 32 & 25 & \\
\hline
\end{tabular}

$\mathrm{P}<0.05$ was considered to indicate a statistically significant result. NELFE, negative elongation factor R; TNM, Tumor-Node-Metastasis.

Triton X-100 at $37^{\circ} \mathrm{C}$ for $1 \mathrm{~h}$. The membranes were then incubated with the primary antibodies at $4^{\circ} \mathrm{C}$ overnight and the secondary antibodies at room temperature for $1 \mathrm{~h}$. Finally, the results were visualized using an ECL blotting analysis system (GE Healthcare Biosciences). The primary antibodies used in the present study were: Anti-NELFE (catalog no. ab170104; 1:1,000), anti-GAPDH (catalog no. ab8245; 1:5,000), anti-E-cadherin (catalog no. ab1416; 1:1,000), anti-N-cadherin (catalog no. ab202030, 1:1,000), anti-Vimentin (catalog no. ab193555; 1:2,000), anti- $\beta$-catenin (catalog no. ab32572; 1:1,000), anti-NDRG2 (catalog no. ab174850; 1:2,000), anti- $\alpha$-tubulin (catalog no. ab210797; $1: 2,000$ ) and anti-LaminB1 (catalog no. ab252351; 1:2,000) (all from Abcam). The goat anti-rabbit secondary antibody (1:10,000; cat. no. bs-40295G-IRDye8) was purchased from Beijing Bioss Biotechnology. Finally, the membranes were tested using a bio-imaging system (DNR Bio-Imaging Systems). ImageJ software (version 1.6.0; National Institutes of Health) was used to quantify the intensity of protein bands and normalized by GAPDH.

MTT assays. The PC cells were seeded into the 96-well plates at a density of 500-700 cells per well. The cells in each well were cultured in $100 \mu \mathrm{l}$ DMEM medium with $10 \% \mathrm{FBS}$. At the time points $0,24,48,72$ and $96 \mathrm{~h}$, MTT solution $(10 \mu \mathrm{l}$,
$5 \mathrm{mg} / \mathrm{ml}$ ) were added into the culture medium. After incubation for $4 \mathrm{~h}$ at room temperature, the medium containing MTT solution was removed, and dimethyl sulfoxide (DMSO; volume, $200 \mu \mathrm{l}$; concentration, $1 \mathrm{mg} / \mathrm{ml}$ ) was added into each well to dissolve the purple formezan. Finally, the plate reader (Bio-Rad Laboratories) was used to observe the absorbance at the $492 \mathrm{~nm}$ wavelength.

Colony-forming assays. A total of 100 PC cells per well were seeded into a 6-well cell culture cluster containing $2 \mathrm{ml}$ DMEM supplemented with $10 \%$ FBS in each well. Following culture in a humidified atmosphere for 10 days at $37^{\circ} \mathrm{C}$, the colonies were fixed with methanol, and then stained in $0.1 \%$ crystal violet solution at $37^{\circ} \mathrm{C}$ for $30 \mathrm{~min}$. The cells were then washed with PBS 2-3 times and then dried overnight. The colonies forming units (consisting of $\geq 50$ cells) were assessed under an inverted fluorescence microscope (Nikon, magnification, $\mathrm{x} 40$ ).

Cell migration and invasion assays. The $8.0 \mu \mathrm{m}$ pore Transwell chambers (EMD Millipore) inserted in 24-well plates were used for the migration and invasion assays. Migration assays: The PC cells $\left(2 \times 10^{4}\right)$ in $200 \mu \mathrm{l}$ serum-free media were applied to the upper chamber, while normal culture media (DMEM supplemented with $10 \% \mathrm{FBS}, 700 \mu \mathrm{l}$ ) was added to the bottom compartment. After incubation in cell incubator for $36 \mathrm{~h}$ 


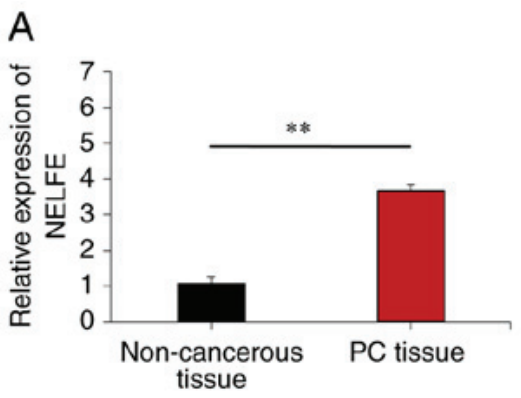

B
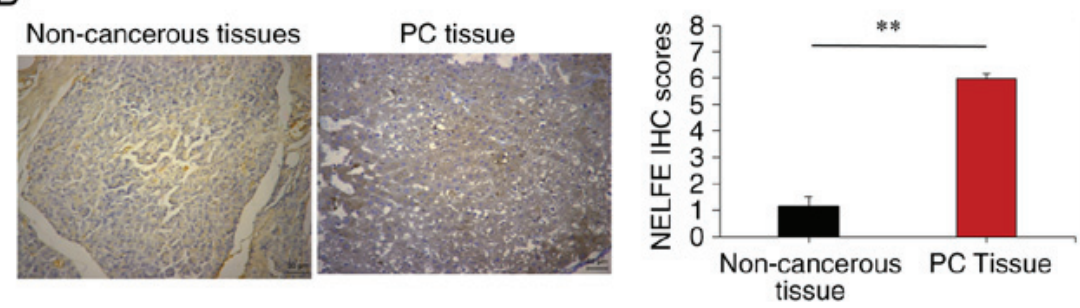

C

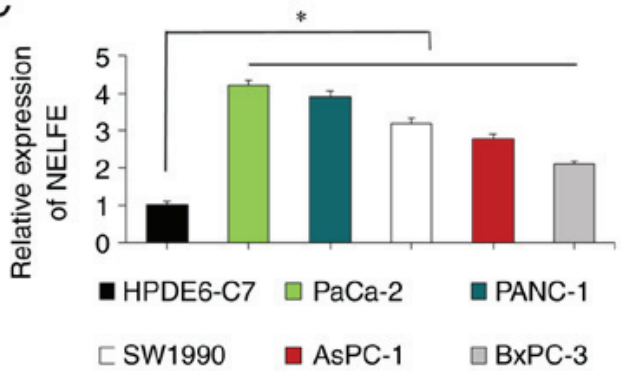

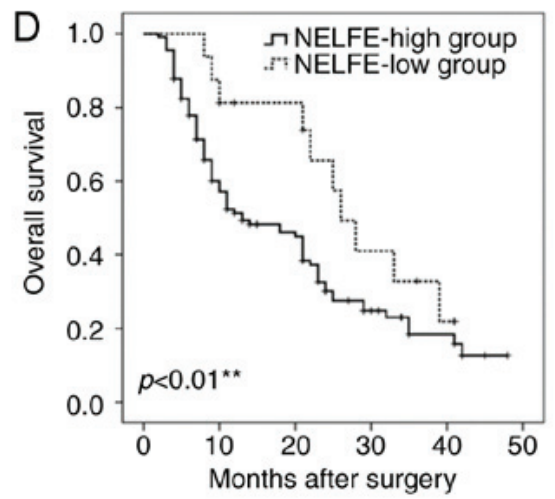

Figure 1. Increased NELFE expression in PC tissues and cells. (A) The expression of NELFE in samples was analyzed by reverse transcription-quantitative PCR. (B) Analysis of the expression of NELFE in samples using an immunohistochemistry assay. The positive expression of NELFE was brown and yellow. The nuclei of cells were blue. (C) NELFE expression levels in various human PC cell lines and HPDE6-C7 cells. (D) Comparison of Overall survival between PC patients with high and low NELFE expression levels $(\mathrm{n}=120)$. The 120 pair of $\mathrm{PC}$ tissues and adjacent non-tumor clinical samples were removed from patients with PCs. "P<0.05 vs. HPDE6-C7; *"P $<0.01$ vs. non-cancerous tissues or NELFE-low group. NELFE, negative elongation factor E; PC, pancreatic cancer.

at $37^{\circ} \mathrm{C}$, the invaded cells moved into the lower side of the membranes were fixed with $4 \%$ paraformaldehyde at $37^{\circ} \mathrm{C}$ for $1 \mathrm{~h}$ and then stained with $0.1 \%$ crystal violet solution for $30 \mathrm{~min}$ at $37^{\circ} \mathrm{C}$. Invasion assay: The procedures was same as those aforementioned in the migration assay except that the membranes in the upper chamber were pre-coated with $15 \mu \mathrm{g}$ Matrigel (Becton Dickinson Bioscience). Finally, the migrated cells were examined in 10 randomly selected fields of view under a fluorescence microscope (magnification, x200).

Luciferase reporter assays. The PC cells (1x10 $/$ well) in a 24-well plate were co-transfected with Renilla luciferase (phRL-TK), sh-NELFE vector or sh-NELFE negative control (NC) empty vector, and pGL3-NDRG2-3'UTR reporter vectors (or pGL3-TCF promoter) (GenePharma Co., Ltd.) using Lipofectamine $^{\circledR} 3000$ (1 $\mu \mathrm{l} /$ well; Invitrogen; Thermo Fisher Scientific, Inc.). After transfection for $24 \mathrm{~h}$, the luciferase activities were measured using a Dual-Luciferase Reporter Assay System kit (Promega Corporation) according to the manufacturer's protocol. The relative Firefly luciferase activity was measured by normalizing to Renilla luciferase activity.

$m R N A$ decay assay. The PC cells were seeded into 6-well plates supplemented with actinomycin D (Sigma Aldrich; Merck KGaA) at a concentration of $0.8 \mu \mathrm{g} / \mathrm{ml}$. RT-qPCR assay was performed as aforementioned in order to detect NDRG2 RNA in PC cells at scheduled time points following transfection with sh-NELFE or the control vectors, including 2, 4, 6, 8, 10 and $12 \mathrm{~h}$.

RNA immunoprecipitation (RIP assay). The RIP assay was performed according to the instructions of the RIP
RNA-binding protein Immunoprecipitation kit (EMD Millipore) following the manufacturer's protocol. The PC cell lysates were added with RIP Lysis Buffer and NELFE antibody, normal mouse IgG (negative control) (1:200; cat. no. PP6421-K; EMD Millipore) and agarose beads and incubated overnight at $4^{\circ} \mathrm{C}$. A High-Capacity cDNA Reverse Transcription kit (Thermo Fisher Scientific, Inc.) was used to reverse transcribe the immunoprecipitated RNAs. Finally, RT-qPCR was performed as aforementioned in order to examine the targets transcripts.

Statistical analysis. Statistical analyses were performed using SPSS statistical software (version 19.0; IBM Corp.) and the data are expressed as the mean \pm standard error. Student's t-test was used to evaluate the difference between two groups. The Kaplan-Meier method and log-rank test was used to plot the survival curves. Person correlation was performed in order to assess the correlation between NELFE and NDRG2 mRNA expression in $\mathrm{PC}$ tissues. $\mathrm{P}<0.05$ was considered to indicate a statistically significant result. All experiments were repeated triplicate.

\section{Results}

NELFE is increased in PC tissues and cell lines. In order to determine the expression pattern of NELFE in clinical PC samples, the present study investigated NELFE expression in 120 pairs of PC tissues and adjacent non-tumor clinical samples removed from patients with PC. RT-qPCR assays suggested that NELFE mRNA expression was primarily higher in the PC tissues than in the paired non-cancerous 

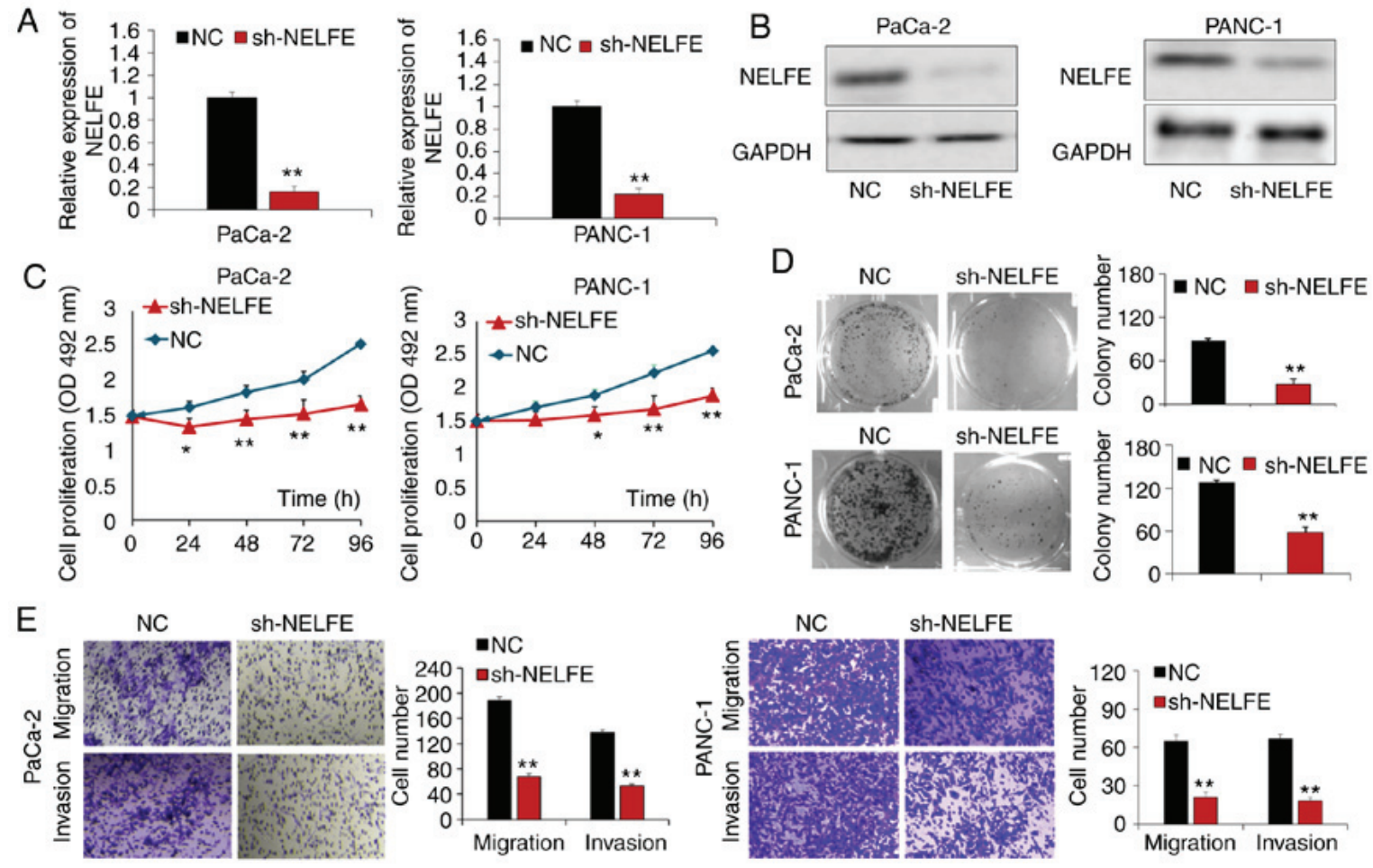

Figure 2. NELFE promoted the malignant biological behavior of PC cells. (A) The mRNA expression of NELFE was decreased following transfection of the NELFE-shRNA vector in PaCa-2 and PANC-1 cells. (B) The protein expression of NELFE was decreased following transfection of the NELFE-shRNA vector in PaCa-2 and PANC-1 cells. (C) MTT assay demonstrated that decreased NELFE suppressed PC cell growth. (D) The decreased NELFE inhibited clone formation of PC cells. (E) Transwell assay revealed that knockdown of NELFE inhibited PC cell invasion and migration. The invaded cells were quantified by counting the cells in 10 randomly selected fields (x200 magnification). All experiments were repeated in triplicate. ${ }^{*} \mathrm{P}<0.05,{ }^{* *} \mathrm{P}<0.01$. NELFE, negative elongation factor E; PC, pancreatic cancer; shRNA, short hairpin RNA; NC, negative control.

tissues $(\mathrm{P}<0.01$; Fig. 1A). Immunohistochemistry assays also revealed that NELFE expression was largely upregulated in PC tissues compared with that in non-cancerous tissues from patients with PC $(\mathrm{P}<0.01$; Fig. 1B). The present study also analyzed the clinical significance of NELFE in patients with PC. A high NELFE expression level was significantly associated with lymph node metastasis $(\mathrm{P}=0.001)$, large tumor size $(\mathrm{P}=0.04)$ and advanced Tumor-Node-Metastasis (TNM) stage $\mathrm{PC}(16)(\mathrm{P}=0.003$; Table I). The present study further measured the expression levels of NELFE in PC cells using RT-qPCR, and the results revealed that the expression level of NELFE was higher in $\mathrm{PC}$ cell lines than in normal pancreatic cells (HPDE6-C7) $(\mathrm{P}<0.05$; Fig. 1C). Among the PC cell lines, the expression of NELFE was highest in the PANC-1 and PaCa-2 cell lines. In addition, the Kaplan-Meier analysis revealed that compared with those with higher levels of NELFE, patients with lower expression levels of NELFE had a shorter survival time ( $\mathrm{P}<0.01$; Fig. 1D).

NELFE promotes PC cell proliferation, invasion and migration. The present study transfected $\mathrm{PaCa}-2$ and PANC-1 cells with a sh-NELFE vector or control vector. RT-qPCR and western blot assays demonstrated that compared with transfection of the control vector, transfection of the sh-NELFE vector markedly decreased the mRNA and protein expression levels of NELFE in PC cells ( $\mathrm{P}<0.01$; Fig. 2A and B). The MTT assay suggested that the proliferation ability of both $\mathrm{PaCa}-2$ and PANC-1 cells was significantly inhibited following knocking-down NELFE expression $(\mathrm{P}<0.05$; Fig. $2 \mathrm{C})$. In addition, the colony formation results demonstrated that downregulated NELFE expression inhibited the PC cell colony formation ability ( $\mathrm{P}<0.01$; Fig. 2D). The present study also performed transwell assays in order to assess the function of NELFE in the migration and invasion ability of PC cells. As presented in Fig. 2E, decreased NELFE significantly suppressed the migration and invasion ability of PC cells $(\mathrm{P}<0.01)$. These results further suggested that NELFE serves as an oncogene in PC cells.

NELFE promotes EMT and Wnt/ $\beta$-catenin signaling in $P C$ cells. EMT is well known as the foundation and key mechanism of the invasion and metastasis of PC cells. Thus, the present study performed a western blot assay to measure the expression levels of epithelial markers (E-cadherin) and mesenchymal markers (N-cadherin and Vimentin) in PC cells transfected with control vector or sh-NELFE vector, in order to investigate whether NELFE promoted PC cell migration and invasion via regulating the EMT. As presented in Fig. 3A, decreased NELFE levels inhibited the expression of mesenchymal markers and enhanced the expression of epithelial markers, which indicated that NELFE promoted PC cell EMT. $\beta$-catenin is recognized as a key effector of $\mathrm{Wnt} / \beta$-catenin signaling, which is widely implicated in EMT in a number of different types of cancer, including PC (17). The results from the present study also revealed that decreased NELFE resulted in the downregulation of $\beta$-catenin expression in PC cells. A decrease in $\beta$-catenin breakdown and its subsequent accumulation in the cytoplasm will facilitate its nuclear translocation. 

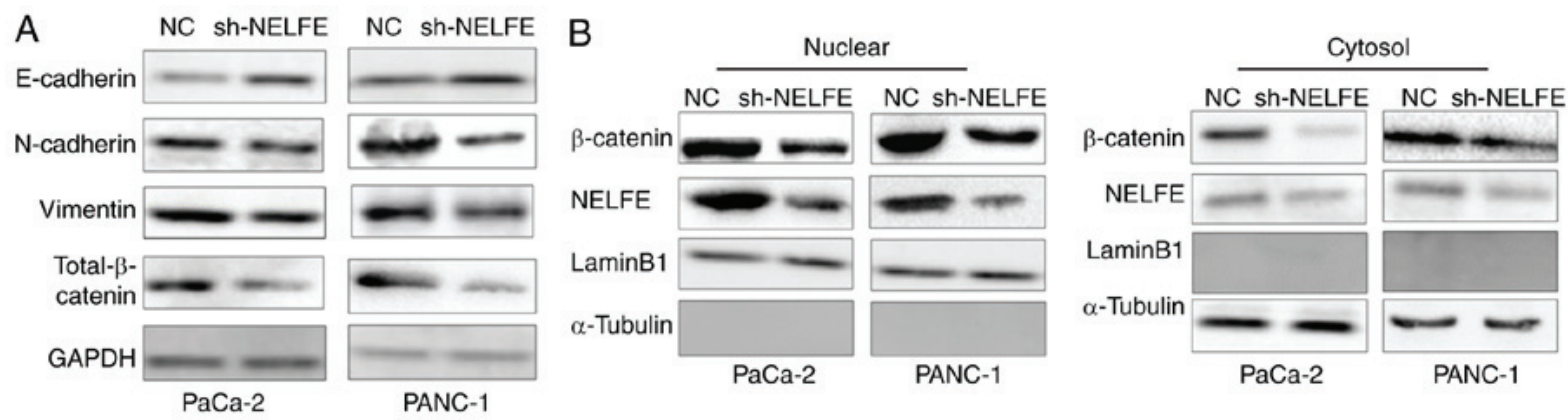

C
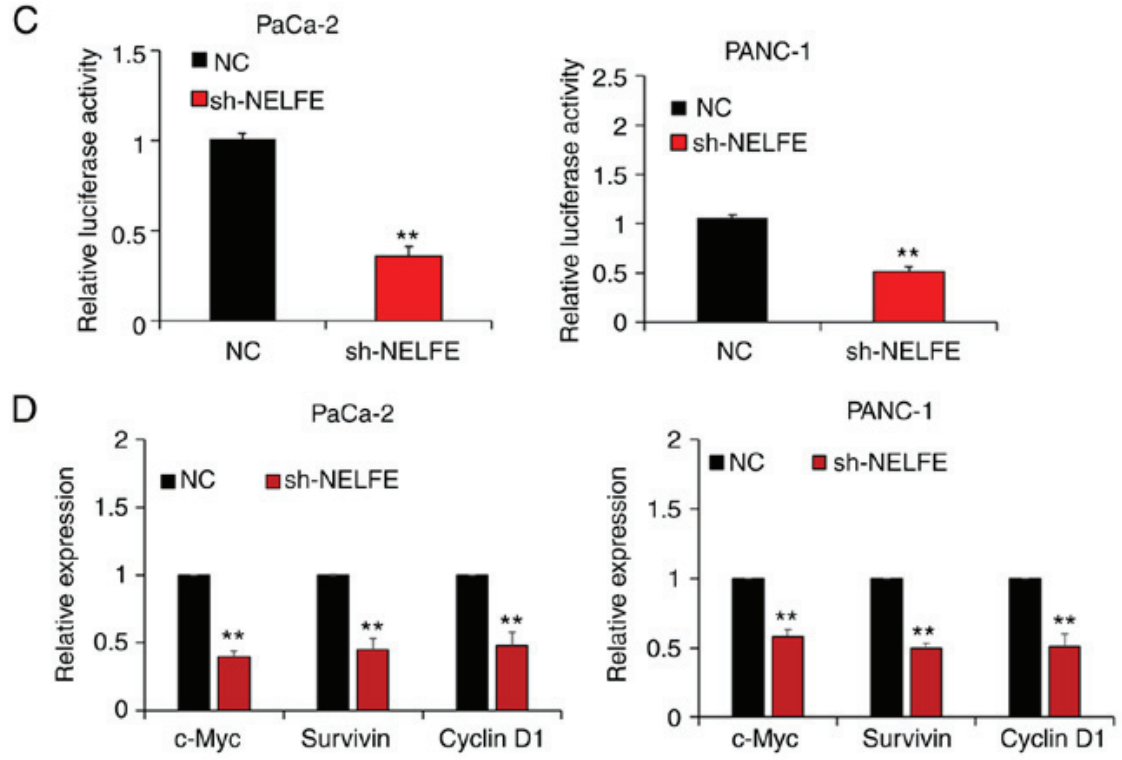

Figure 3. NELFE promoted EMT and Wnt/ $\beta$-catenin signaling way in PC. (A) Western blot analysis of EMT-associated protein and $\beta$-catenin expression after the downregulation of NELFE in PC cells. GAPDH was used as an internal control. (B) Downregulation of NELFE in PC cells reduced the nuclear accumulation of $\beta$-catenin. (C) The dual luciferase reporter assay showed that decreased NELFE inhibited the transactivation of the TCF reporter in PC cells. (D) Reverse transcription-quantitative PCR assay revealed that the expression of the Wnt/ $\beta$-catenin downstream genes (c-Myc, Survivin and cyclinD1) was decreased due to the knockdown of NFLFE in PC cells. All experiments were repeated three times. ${ }^{*} \mathrm{P}<0.05,{ }^{* *} \mathrm{P}<0.01$ vs NC group. NELFE, negative elongation factor E; EMT, epithelial-to-mesenchymal transition; PC, pancreatic cancer; shRNA, short hairpin RNA; NC, negative control.

Then, $\beta$-catenin can bind to TCF transcription factors in the nucleus and successfully transcriptionally activate a series of genes associated with the EMT (18). Thus, the present study performed subcellular fractionation assays in order to evaluate whether NELFE activated the Wnt/ $\beta$-catenin signaling pathway in PC cells. The results revealed that downregulation of NELFE in PC cells markedly decreased the nuclear accumulation of $\beta$-catenin (Fig. 3B). In addition, a dual luciferase reporter assay demonstrated that decreased NELFE significantly inhibited the transactivation of the TCF reporter in PC cells (Fig. 3C). Furthermore, the present study measured the expression levels of $\mathrm{Wnt} / \beta$-catenin target genes, such as c-Myc, survivin and cyclin D1, via RT-qPCR. The results revealed that $\mathrm{Wnt} / \beta$-catenin downstream gene expression was significantly downregulated following NELFE knockdown in PC cells (Fig. 3D). Overall, these results suggested that NELFE promotes EMT via activating the Wnt/ $\beta$-catenin signaling pathway in PC.

NELFE activates the Wnt/ $\beta$-catenin signaling pathway by inhibiting NDRG2 expression in PC. NDRG2, a tumor suppressor belonging to the NDRG family, has been reported to be decreased in human cancer tissues, including PC (19).
Accumulating studies have revealed that NDRG2 is involved in the regulation of EMT via inhibiting $\beta$-catenin/c-Myc signaling and then inducing E-cadherin degradation in human cancers (20-22). Notably, the present study aimed to determine the potential molecular mechanisms underlying the regulation of the Wnt/ $\beta$-catenin signaling pathway by NELFE, and revealed that NDRG2 expression was strongly increased following NELFE knockdown (Fig. 4A). In addition, the present study performed a RT-qPCR to assess whether there is a correlation between the mRNA expression levels of these two genes in clinical samples of PC tissues. The pearson correlation analysis of RT-qPCR results revealed that NELFE mRNA levels were negatively correlated with NDRG2 mRNA levels $(\mathrm{R}=-0.776, \mathrm{P}<0.01$; Fig. 4B). Thus, it was speculated that NELFE may activate the Wnt/ $\beta$-catenin signaling pathway by inhibiting the expression of NDRG2. The present study transfected the sh-NDRG2 vector or control vector into PC cells with NELFE knockdown. As presented in Fig. 4C, knockdown of NDRG2 in PC cells with decreased NELFE increased the expression levels of total $\beta$-catenin (including nuclear $\beta$-catenin and cytosol $\beta$-catenin) and mesenchymal markers $(\mathrm{N}$-cadherin and Vimentin), and decreased the expression level of an epithelial marker (E-cadherin) (Fig. 4C). In addition, knockdown 
A

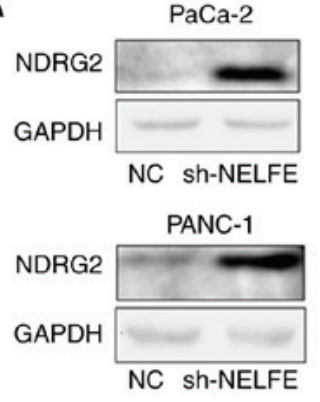

B

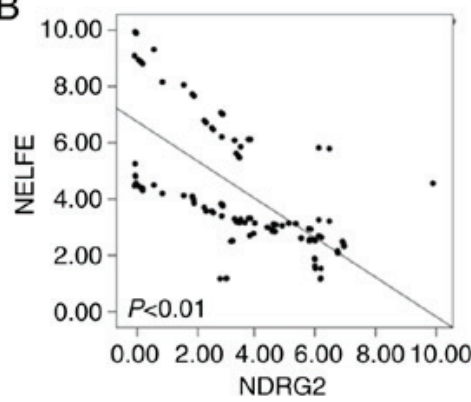

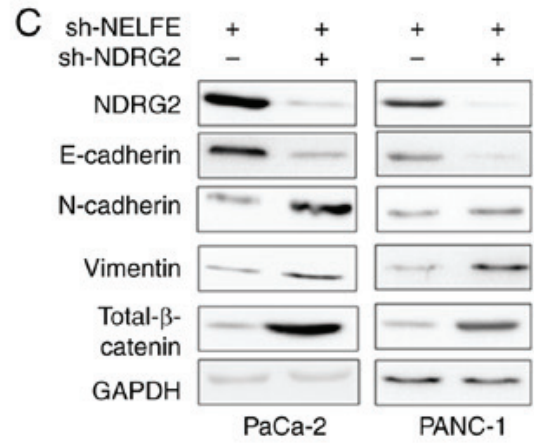

D

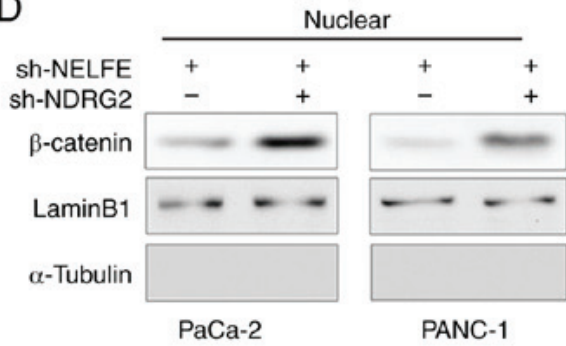

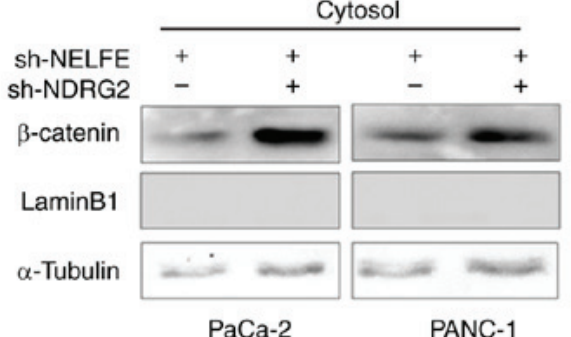

$\mathrm{F}$
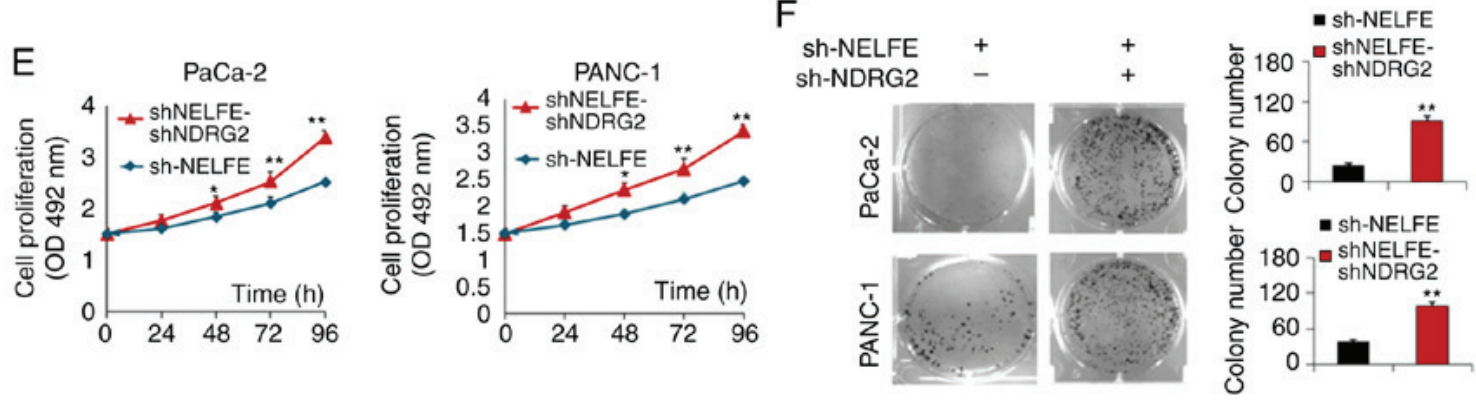

\section{G}
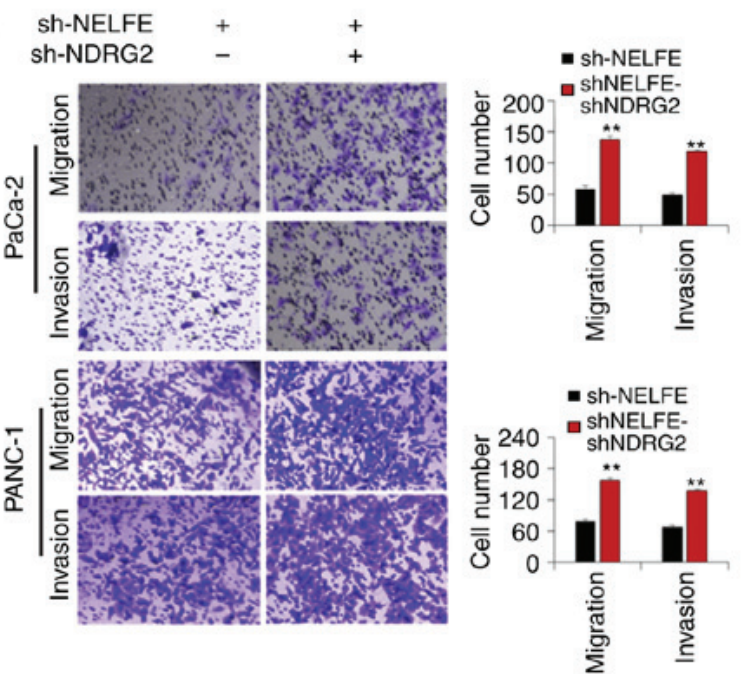

Figure 4. NDRG2 is an essential downstream effect of NELFE in PC. (A) NDRG2 expression was measured by western blotting in PC cells with NELFE knockdown. (B) The correlation between NELFE and NDRG2 mRNA expression in 120 samples from patients with PC was analyzed via person correlation analysis $(\mathrm{R}=-0.776)$. (C) Western blot analysis of associated protein and $\beta$-catenin expression following the downregulation of NDRG2 in PC cells with decreased NELFE. (D) Decreased NDRG2 enhanced the nuclear accumulation of $\beta$-catenin in PC cells with decreased NELFE. (E) MTT assay showed downregulation of NDRG2 rescued the function of sh-NELFE on PC cells proliferation. (F) The downregulation of NDRG2 rescued the function of decreased NELFE on PC cells colony formation ability. (G) Knockdown of NDRG2 rescued the inhibition function of decreased NELFE on PC cells migration and invasion. The PC cells with NELFE-NDRG2 double knockdown cells were used in the panels of C-G. All experiments were repeated in triplicate. "P $<0.05$, ${ }^{* *} \mathrm{P}<0.01$ vs. NC group. NDRG2, N-Myc downstream-regulated gene 2; NELFE, negative elongation factor E; EMT, epithelial-to-mesenchymal transition; PC, pancreatic cancer; shRNA, short hairpin RNA; NC, negative control.

of NDRG2 promoted the nuclear accumulation of $\beta$-catenin in PC cells, even though the expression of NELFE was downregulated (Fig. 4D). Furthermore, sh-NDRG2-mediated downregulation of NDRG2 significantly promoted the proliferation, invasion and migration of sh-NELFE-transfected PC cells (Fig. 4E-G). Taken together, these results suggested that 
A

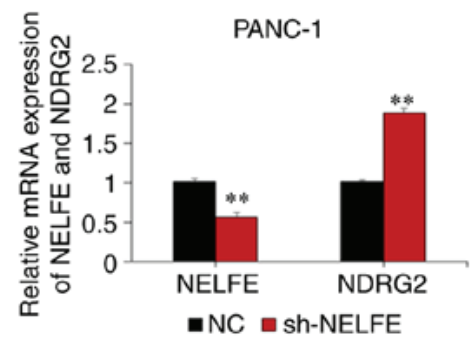

B

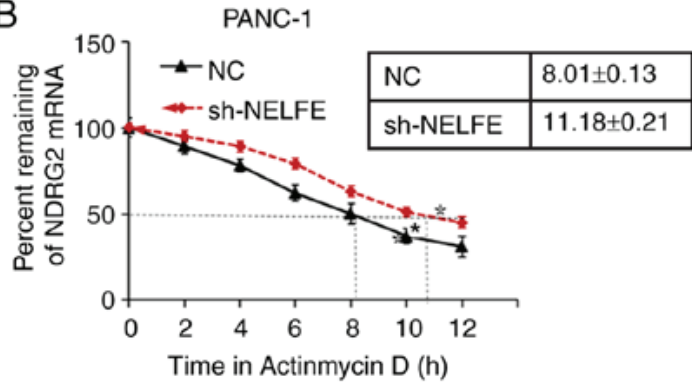

C

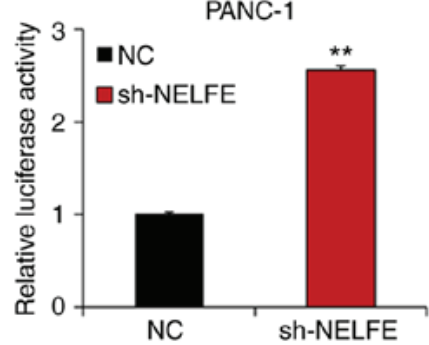

D

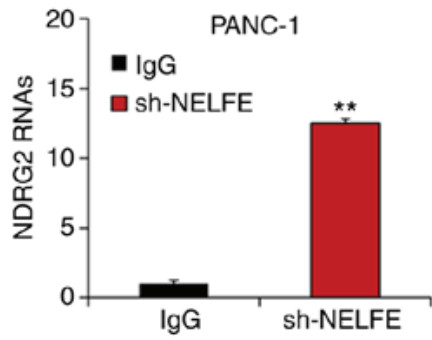

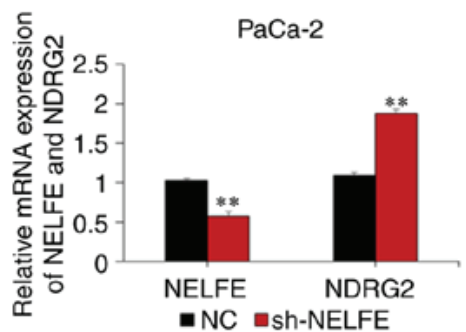

PaCa-2

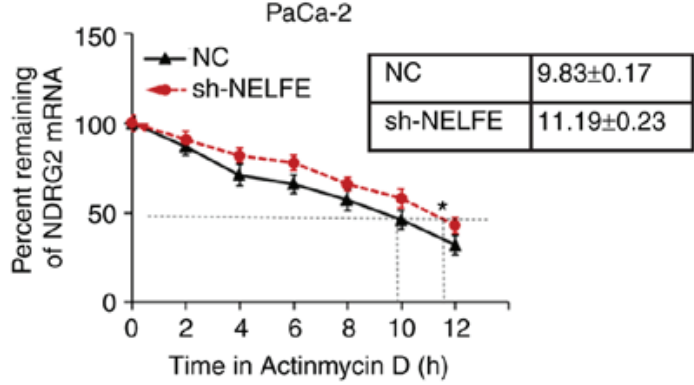

PaCa-2
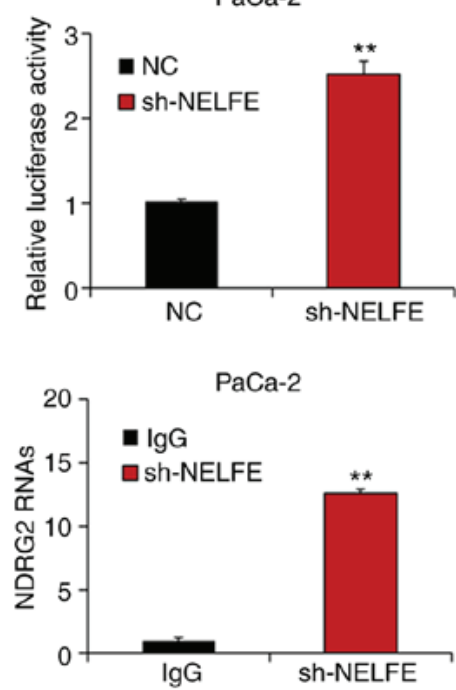

Figure 5. NELFE decreased NDRG2 by interacting with its mRNA. (A) Reverse transcription-quantitative PCR results revealed that the mRNA levels of NDRG2 were increased following the knockdown of NELFE. (B) The half-life NDRG2 mRNA increased after NELFE knockdown in PC cells. (C) The decreased NELFE enhanced the luciferase activity of NDRG2 3'untranslated region. (D) RNA immunoprecipitation assays demonstration NELFE directly binding to NDRG2 mRNA. All experiments were repeated three times. ${ }^{*} \mathrm{P}<0.05,{ }^{*} \mathrm{P}<0.01$ vs. NC group. NEFLE, negative elongation factor E; NDRG2, N-Myc elongation factor E; PC, pancreatic cancer.

NELFE activated the Wnt/ $\beta$-catenin signaling pathway and promoted PC tumor progression in a manner at least partly dependent on NDRG2 expression downregulation.

NELFE decreases NDRG2 expression by directly interacting with its $m R N A$. The RT-qPCR results further demonstrated that the mRNA expression level of NDRG2 was significantly increased following NELFE knockdown (Fig. 5A), suggesting that NELFE regulated NDRG2 at the transcriptional level. The effect of NELFE on the stability of NDRG2 mRNA was also measured, and the results revealed that the half-life of NDRG2 mRNA was prolonged after NELFE was decreased in PC cells (Fig. 5B). A luciferase reporter assay demonstrated that decreased NELFE enhanced the luciferase activity of the NDRG2 3' UTR (Fig. 5C). In order to further investigate whether NELFE binds directly to
NDRG2 mRNA, the present study performed RIP assays, and the results revealed that NDRG2 mRNA was more enriched in sh-NELFE transfected PC cells than the control (IgG) (Fig. 5D). Thus, the results from the present study demonstrated that NELFE inhibited NDRG2 expression by promoting decay of its transcript.

\section{Discussion}

To the best of our knowledge, the present study is the first to demonstrate that NELFE acts as an RBP to promote EMT and metastasis in PC by activating the Wnt/ $\beta$-catenin signaling pathway via post-transcriptional inhibition of NDRG2 expression. The data from the present study contributes to the current understanding of the molecular mechanism by which NELFE overexpression promotes tumorgenesis and progression in PC. 
NELFE is an important part of NELF, which is well known as the pivotal regulatory factor of the Pol II pausing complex $(12,23,24)$. NELF contains four multi-functional sub-units, NELFA, NELFB, NELFC and NELFE, which are all involved in the regulation of MYC signaling (25-27). In addition, the four sub-units have been identified to be involved in a variety of different types of human cancer $(23,28,29)$. Midorikawa et al (26) reported that the overexpression of NELFE contributed to the tumorigenesis of hepatocellular carcinoma (HCC). A recent study demonstrated that NELFE is upregulated in HCC tissues, and the overexpression of NELFE promoted the progression of $\mathrm{HCC}$ via directly binding to and enhancing MYC (13). Further research on the role of NELF will be helpful for understanding the potential molecular mechanism of PC, and may provide a novel treatment strategy. To the best of our knowledge, the present study demonstrated for the first time that NELFE was increased in PC tissues and cell lines. These data are consistent with other recent results suggesting that NELFE functions as an oncogene in human cancers (13). The present study further confirmed that the upregulation of NELFE was associated with poor outcomes in patients with PC. In addition, the in vitro results demonstrated that NELFE downregulation weakened the proliferation, invasion and migration capacities of PC cells, suggesting that NELFE enhanced the malignant biological behavior of PC cells. Considering these results have indicated the lower expression of NELFE in adjacent non-cancerous tissues from PC patients and normal cells, respectively, compared with that in the PC tissue and PC cell lines, it was speculated that the abnormally increased expression of NELFE is associated with the development and progression of PC. These data strongly suggest that NELFE may work as a potential therapeutic target for patients with PC.

PC is characterized as one of the most aggressive types of human tumor, which causes its high probability of cancer-associated mortality. The poor outcome is in part associated with the high rate of metastasis for patients with PC. Thus, it is important to further understand the potential molecular mechanisms underlying the role of NELFE in promoting PC metastasis. EMT is recognized as a response to the metastasis of human cancer (30), and in this process, epithelial cells lose differentiation characteristics, such as cell adhesion and cell polarity, and are transformed into mesenchymal cells and gain the ability to invade and migrate (31). The present study used a western blot assay to demonstrate that knockdown of NELFE significantly increased E-cadherin expression and decreased $\mathrm{N}$-cadherin and vimentin expression in PC cells. These data suggest that NELFE promotes EMT in PC cells. Previous research has revealed that a series of signaling factors participate in the regulation of EMT processes (32), including Wnt/ $\beta$-catenin, TGF- $\beta$, Notch and HIF-1 $\alpha$ (33-35). Among these signaling pathways, Wnt/ $\beta$-catenin is well known to serve as the key mediator of EMT (36). The western blot assay results revealed that decreased NELFE inhibited the expression and nuclear accumulation of $\beta$-catenin, suggesting that NELFE promoted EMT via activating the Wnt $/ \beta$-catenin signaling pathway in PC.

Although increasing research has been focused on the involvement of RBPs in a range of different types of human cancer in previous years (37-39), more studies on the details of the biological effect and underlying mechanisms of RBPs are still required. To the best of our knowledge, the present study provided the first evidence that NELFE acts as an RBP to promote $\mathrm{PC}$ tumorigenesis and metastasis via the post-transcriptional regulation of NDRG2 expression. NELFE has been verified to contain an RNA recognition motif domain (40), which preferentially binds directly to RNAs. At first, studies focused on only NELFE revealed that it binds to certain special RNAs $(41,42)$. Until recently, the role of NELFE in the regulation of human cancer progression through binding to certain target genes began to attract researchers' interest $(13,43)$. The present study identified NDRG2 as a target gene of NELFE in PC. The use of the luciferase, mRNA decay and RIP assays demonstrated that NELFE inhibits NDRG2 expression by binding directly to its 3'UTR. NDRG2 is involved in the regulation of cancer cell differentiation and proliferation as a tumor suppressor (19). Accumulating studies revealed that NDRG2 expression was significantly lower in various cancer tissues, including liver cancer, pancreatic cancer and glioblastoma, compared with normal tissues, and decreased NDRG2 expression was closely associated with a shorter overall survival in patients with tumors $(22,44)$. NDRG2 has been revealed to regulate the EMT of human cancer in a series of reports. Chen et al (45) reported that NDRG2 suppressed human cancer upon the metabolic reprogramming. Kim et al (46) demonstrated that NDRG2 repressed breast cancer EMT via STAT3/Snail signaling. It has also been confirmed that NDRG2 could inhibit the prostate cancer cell invasion and migration through regulating EMT-associated genes (47) and suppress EMT of esophageal cancer cells via regulating the AKT/XIAP signaling pathway (48). Notably, other studies have confirmed that NDRG2 plays a pivotal role in the modulation of EMT by inhibiting $\beta$-catenin expression $(49,50)$. Thus, the results of the present study are rational. The present study also demonstrated that NDRG2 could contribute to rescuing the function of NELFE in PC cell invasion and migration, further suggesting that NELFE promoted PC metastasis and EMT by activating the $\mathrm{Wnt} / \beta$-catenin signaling pathway via inhibiting NDRG2 expression. These results may help to open novel avenues for treatment strategies for PC.

In summary, to the best of our knowledge, the present study revealed the overexpression of NELFE in PC for the first time. The overexpression of NELFE promoted malignant phenotypes in PC cells, including proliferation, migration and invasion. In addition, the results demonstrated that NELFE promoted the EMT by enhancing the expression and nuclear accumulation of $\beta$-catenin. The present study further revealed that NELFE inhibited NDRG2 expression via binding with its 3'UTR. The present study also revealed the significant role of NDRG2 in mediating the function of NELFE in PC cells. The data also demonstrated for the first time the significance of the NELFE/Wnt/ $\beta$-catenin/NDRG2 axis in PC and may offer a novel therapeutic strategy for PC.

\section{Acknowledgements}

Not applicable.

\section{Funding}

The present study was funded by the Natural Science Foundation of Shaanxi Province (grant no. 2019JQ-128) and 
the China Postdoctoral Science General Financial Grant (grant no. 2017M623193).

\section{Availability of data and materials}

The datasets used and/or analyzed during the present study are available from the corresponding author upon reasonable request.

\section{Authors' contributions}

LH collected the clinical samples and performed most of the experiments. YZ performed the experiments and the statistical analysis. $\mathrm{CH}$ conceived and designed the study. SZ assisted with the design of the study and drafting of the manuscript. All authors have read and approved the final version of this published manuscript.

\section{Ethics approval and consent for publication}

The present study was approved by the Ethics Committee of Clinical Research of Xi'an Jiaotong University (Xi'an, China) and was performed in accordance with the 1964 Declaration of Helsinki. Written informed consent was obtained from all patients prior to the study start.

\section{Patient consent for publication}

Not applicable.

\section{Competing interests}

The authors declare that they have no competing interests.

\section{References}

1. Siegel RL, Miller KD and Jemal A: Cancer statistics 2017. CA Cancer J Clin 67: 7-30, 2017.

2. Wang L, Yang GH, Li H and $\mathrm{Lu} \mathrm{XH}$ : The changing pancreatic cancer mortality in China (1991-2000). Zhonghua Nei Ke Za Zhi 44: 509-513, 2005 (In Chinese).

3. Worni M, Guller U, White RR, Castleberry AW, Pietrobon R, Cerny T, Gloor B and Koeberle D: Modest improvement in overall survival for patients with metastatic pancreatic cancer: A trend analysis using the surveillance, epidemiology, and end results registry from 1988 to 2008. Pancreas 42: 1157-1163, 2013.

4. Nieto MA, Huang RY, Jackson RA and Thiery JP: EMT: 2016. Cell 166: 21-45, 2016.

5. Giannelli G, Koudelkova P, Dituri F and Mikulits W: Role of epithelial to mesenchymal transition in hepatocellular carcinoma. J Hepatol 65: 798-808, 2016.

6. Gonzalez DM and Medici D: Signaling mechanisms of the epithelial-mesenchymal transition. Sci Signal 7: re8, 2014.

7. Lee JM, Dedhar S, Kalluri R and Thompson EW: The epithelial-mesenchymal transition: New insights in signaling, development, and disease. J Cell Biol 172: 973-981, 2006.

8. Scaturrok M, Sala A, Cutrona G, Raimondi L, Cannino G, Fontana S, Pucci-Minafra I and Di Liegro I: Purification by affinity chromatography of H1o RNA-binding proteins from rat brain. Int J Mol Med 11: 509-513, 2003.

9. Roesch A, Becker B, Meyer S, Wild P, Hafner C, Landthaler M and Vogt T: Retinoblastoma-binding protein 2-homolog 1: A retinoblastoma-binding protein downregulated in malignant melanomas. Mod Pathol 18: 1249-1257, 2005.

10. Hodson DJ, Screen M and Turner M: RNA binding proteins in hematopoiesis and hematological malignancy. Blood 133: 2365-2373, 2019.
11. Hentze MW, Castello A, Schwarzl T and Preiss T: A brave new world of RNA-binding proteins. Nat Rev Mol Cell Biol 19: 327-341, 2018.

12. Narita T, Yung TM, Yamamoto J, Tsuboi Y, Tanabe H, Tanaka K, Yamaguchi Y and Handa H: NELF interacts with CBC and participates in 3' end processing of replication-dependent histone rnRNAs. Mol Cell 26: 349-365, 2007.

13. Dang H, Takai A, Forgues M, Pomyen Y, Mou H, Xue W, Ray D, Ha KCH, Morris QD, Hughes TR and Wang XW: Oncogenic activation of the RNA binding protein NELFE and MYC signaling in hepatocellular carcinoma. Cancer Cell 32: 101-114.e8, 2017.

14. Han LL, Nan HC, Tian T, Guo H, Hu TH, Wang WJ, Ma JQ, Jiang LL, Guo QQ, Yang CC, et al: Expression and significance of the novel tumor-suppressor gene SMG-1 in hepatocellular carcinoma. Oncol Rep 31: 2569-2578, 2014.

15. Livak KJ and Schmittgen TD: Analysis of relative gene expression data using real-time quantitative PCR and the 2(-Delta Delta C (T)) method. Methods 25: 402-408, 2001

16. Liu L, Xu HX, He M, Wang W, Wang WQ, Wu CT, Wei RQ, Liang Y, Gao HL, Liu C, et al: A novel scoring system predicts postsurgical survival and adjuvant chemotherapeutic benefits in patients with pancreatic adenocarcinoma: Implications for AJCC-TNM staging. Surgery 163: 1280-1294, 2018.

17. Zhou P, Li Y, Li B, Zhang M, Liu Y, Yao Y and Li D: NMIIA promotes tumor growth and metastasis by activating the Wnt/ $\beta$-catenin signaling pathway and EMT in pancreatic cancer. Oncogene 38: 5500-5515, 2019.

18. Tian X, Liu Z, Niu B, Zhang J, Tan TK, Lee SR, Zhao Y, Harris DC and Zheng G: Ecadherin/ $\beta$-catenin complex and the epithelial barrier. J Biomed Biotechnol 2011: 567305, 2011.

19. Lorentzen A, Vogel LK, Lewinsky RH, Saebø M, Skjelbred CF, Godiksen S, Hoff G, Tveit KM, Lothe IM, Ikdahl T, et al: Expression of NDRG2 is down-regulated in high-risk adenomas and colorectal carcinoma. BMC Cancer 7: 192, 2007.

20. Kang K, Nam S, Kim B, Lim JH, Yang Y, Lee MS and Lim JS: Inhibition of osteoclast differentiation by overexpression of NDRG2 in monocytes. Biochem Biophys Res Commun 468: 611-616, 2015.

21. Zhang J, Li F, Liu X, Shen L, Liu J, Su J, Zhang W, Deng Y, Wang L, Liu N, et al: The repression of human differentiation-related gene NDRG2 expression by Myc via Miz-1-dependent interaction with the NDRG2 core promoter. J Biol Chem 281: 39159-39168, 2006.

22. Hu XL, Liu XP, Lin SX, Deng YC, Liu N, Li X and Yao LB: NDRG2 expression and mutation in human liver and pancreatic cancers. World J Gastroenterol 10: 3518-3521, 2004.

23. Yamaguchi Y, Takagi T, Wada T, Yano K, Furuya A, Sugimoto S, Hasegawa $J$ and Handa H: NELF, a multisubunit complex containing RD, cooperates with DSIF to repress RNA polymerase II elongation. Cell 97: 41-51, 1999.

24. Vos SM, Pöllmann D, Caizzi L, Hofmann KB, Rombaut P, Zimniak T, Herzog F and Cramer P: Architecture and RNA binding of the human negative elongation factor. Elife 5: e14981, 2016.

25. Price DH: Regulation of RNA polymerase II elongation by c-Myc. Cell 141: 399-400, 2010.

26. Midorikawa Y, Tsutsumi S, Taniguchi H, Ishii M, Kobune Y, Kodama T, Makuuchi M and Aburatani H: Identification of genes associated with dedifferentiation of hepatocellular carcinoma with expression profiling analysis. Jpn J Cancer Res 93: 636-643, 2002.

27. McChesney PA, Aiyar SE, Lee OJ, Zaika A, Moskaluk C, Li R and El-Rifai W: Cofactor of BRCA1: A novel transcription factor regulator in upper gastrointestinal adenocarcinomas. Cancer Res 66: 1346-1353, 2006.

28. Wu CH, Lee C, Fan R, Smith MJ, Yamaguchi Y, Handa H and Gilmour DS: Molecular characterization of Drosophila NELF. Nucleic Acids Res 33: 1269-1279, 2005.

29. Sun J, Watkins G, Blair AL, Moskaluk C, Ghosh S, Jiang WG and Li R: Deregulation of cofactor of BRCA1 expression in breast cancer cells. J Cell Biochem 103: 1798-1807, 2008.

30. Thiery JP and Sleeman JP: Complex networks orchestrate epithelial-mesenchymal transitions. Nat Rev Mol Cell Biol 7: 131-142, 2006.

31. Cui W, Meng W, Zhao L, Cao H, Chi W and Wang B: TGF- $\beta$-induced long non-coding RNA MIR155HG promotes the progression and EMT of laryngeal squamous cell carcinoma by regulating the miR-155-5p/SOX10 axis. Int J Oncol 54: 2005-2018, 2019 
32. Nie J, Jiang HC, Zhou YC, Jiang B, He WJ, Wang YF and Dong J: MiR-125b regulates the proliferation and metastasis of triple negative breast cancer cells via the Wnt/ $\beta$-catenin pathway and EMT. Biosci Biotechnol Biochem 83: 1062-1071, 2019.

33. Zhang HG, Pan YW, Feng J, Zeng CT, Zhao XQ, Liang B and Zhang WW: TRIM66 promotes malignant progression of hepatocellular carcinoma by inhibiting E-cadherin expression through the EMT pathway. Eur Rev Med Pharmacol Sci 23: 2003-2012, 2019.

34. Nam Y, Weng AP, Aster JC and Blacklow SC: Structural requirements for assembly of the CSL.intracellular Notch1. Mastermind-like 1 transcriptional activation complex. J Biol Chem 278: 21232-21239, 2003.

35. Peng G and Liu Y: Hypoxia-inducible factors in cancer stem cells and inflammation. Trends Pharmacol Sci 36: 374-383, 2015.

36. Oh SJ, Shin JH, Kim TH, Lee HS, Yoo JY, Ahn JY, Broaddus RR, Taketo MM, Lydon JP, Leach RE, et al: $\beta$-Catenin activation contributes to the pathogenesis of adenomyosis through epithelial-mesenchymal transition. J Pathol 231: 210-222, 2013

37. Kechavarzi B and Janga SC: Dissecting the expression landscape of RNA-binding proteins in human cancers. Genome Biol 15: R14, 2014.

38. Gerstberger S, Hafner $M$ and Tuschl T: A census of human RNA-binding proteins. Nat Rev Genet 15: 829-845, 2014.

39. Galante PA, Sandhu D, de Sousa Abreu R, Gradassi M, Slager N, Vogel C, de Souza SJ and Penalva LO: A comprehensive in silico expression analysis of RNA binding proteins in normal and tumor tissue: Identification of potential players in tumor formation. RNA Biol 6: 426-433, 2009.

40. Adelman K and Lis JT: Promoter-proximal pausing of RNA polymerase II: Emerging roles in metazoans. Nat Rev Genet 13 : 720-731, 2012.

41. Li J, Liu Y, Rhee HS, Ghosh SK, Bai L, Pugh BF and Gilmour DS: Kinetic competition between elongation rate and binding of NELF controls promoter proximal pausing. Mol Cell 50: 711-722, 2013.

42. Pagano JM, Kwak H, Waters CT, Sprouse RO, White BS, Ozer A, Szeto K, Shalloway D, Craighead HG and Lis JT: Defining NELF-E RNA binding in HIV-1 and promoter-proximal pause regions. PLoS Genet 10: e1004090, 2014.
43. Dang H, Pomyen Y, Martin SP, Dominguez DA, Yim SY, Lee JS, Budhu A, Shah AP, Bodzin AS and Wang XW: NELFE-dependent MYC signature identifies a unique cancer subtype in hepatocellular carcinoma. Sci Rep 9: 3369, 2019.

44. Deng Y, Yao L, Chau L, Ng SS, Peng Y, Liu X, Au WS, Wang J, Li F, Ji S, et al: N-Myc downstream-regulated gene 2 (NDRG2) inhibits glioblastoma cell proliferation. Int J Cancer 106: 342-347, 2003.

45. Chen XL, Lei L, Hong LL and Ling ZQ: Potential role of NDRG2 in reprogramming cancer metabolism and epithelial-tomesenchymal transition. Histol Histopathol 33: 655-663, 2018.

46. Kim MJ, Lim J, Yang Y, Lee MS and Lim JS: N-myc downstream-regulated gene 2 (NDRG2) suppresses the epithelial-mesenchymal transition (EMT) in breast cancer cells via STAT3/Snail signaling. Cancer Lett 354: 33-42, 2014.

47. Moradi Monfared M, Alizadeh Zarei M, Rafiei Dehbidi G, Behzad Behbahani A, Arabsolghar R and Takhshid MA: NDRG2 regulates the expression of genes involved in epithelial mesenchymal transition of prostate cancer cells. Iran J Med Sci 44: 118-126, 2019

48. Yang CL, Zheng XL, Ye K, Ge H, Sun YN, Lu YF and Fan QX: NDRG2 suppresses proliferation, migration, invasion and epithelial-mesenchymal transition of esophageal cancer cells through regulating the AKT/XIAP signaling pathway. Int J Biochem Cell Biol 99: 43-51, 2018

49. Kim YJ, Yoon SY, Kim JT, Song EY, Lee HG, Son HJ, Kim SY, Cho D, Choi I, Kim JH and Kim JW: NDRG2 expression decreases with tumor stages and regulates $\mathrm{TCF} / \mathrm{beta}$-catenin signaling in human colon carcinoma. Carcinogenesis 30: 598-605, 2009

50. Xu X, Li J, Sun X, Guo Y, Chu D, Wei L, Li X, Yang G, Liu X, Yao L, et al: Tumor suppressor NDRG2 inhibits glycolysis and glutaminolysis in colorectal cancer cells by repressing c-Myc expression. Oncotarget 6: 26161-26176, 2015.

This work is licensed under a Creative Commons Attribution-NonCommercial-NoDerivatives 4.0 International (CC BY-NC-ND 4.0) License. 